minute. Airway hypoxia was discontinued as soon as possible in each infant who showed this degree of desaturation; it should be remembered that this required the tent to be opened and the gas mixture to be removed from around the baby. No infant remained at $\leqslant 80 \%$ in $15 \%$ oxygen for longer than 126 seconds.

Of the four infants in whom exposure to hypoxia was discontinued early, one infant had a sibling who had died of the sudden infant death syndrome and was already being monitored at home. Oxygen saturation levels in all four infants remained within the normal range during subsequent monitoring. We believed that monitoring the infants for a longer period in hospital would not have been ethically appropriate because they might be exposed to additional risks (for example, the risk of acquiring an infection in hospital). The two infants who had died following an aircraft flight were not monitored so we are unaware of the duration and degree of hypoxaemia to which they might have been exposed.

Although Savulescu's commentary raises the spectre of human or mechanical error, we took every precaution to ensure that the infants were safe. These included the use of a special medical gas mixture of $15 \%$ oxygen and $85 \%$ nitrogen instead of air diluted with nitrogen, continuous monitoring of the partial pressure of inspired carbon dioxide to identify rebreathing, and continuous monitoring of the partial pressure of inspired oxygen to ensure adequate ventilation of the tent with the gas mixture. The study was done in a room near the intensive care unit. There was also continuous surveillance by an experienced paediatrician of the readings from the pulse oximeter, transcutaneous monitoring of the partial pressure of carbon dioxide, monitoring of respiratory movement, and electrocardiography.

Although Milner reports in his editorial that British Airways identified no deaths on the undisclosed number of flights involving infants, this is low quality information. It is not accurate, as shown by the personal communication cited in our paper. Infant stimulation and the attention paid to an infant during an airline flight may delay potentially serious consequences of the flight until after the plane's arrival. British Airways would not have access to information on infants after arrival and did not seem to know about either of the two cases of the sudden infant death syndrome that were described in our report.

Heath D. Missing link from Tibet. Thorax 1989;44:981-3.

2 Samuels MP, Poets CF, Southall DP. Abnormal hypoxemia after life-threatening events in infants born before term. I Pediatr 1994;125:441-6.

3 Werthammer J, Brown ER, Neff RK, Taeusch HW. Sudden infant death syndrome in infants with bronchopulmonary dysplasia. Pediatrics 1982;69:301-4

4 Oades PJ, Buchdahl RM, Bush A. Prediction of hypoxaemia at high altitude in children with cystic fibrosis. BMJ 1994;308:15-8.

5 Lozano JM, Duque OR, Buitrago T, Behaine S. Pulse oximeter reference values at high altitude. Arch Dis Child 1992;67:299-301.

6 Niermeyer S, Yang P, Drolkar S, Zhuang J, Moore LG. Arterial oxygen saturation in Tibetan and Han infants born in Lhasa, Tibet. $N$ Engl J Med 1995;333:1248-52.

7 Poets CF, Stebbens VA, Southall DP. Arterial oxygen saturation and breathing movements during the first year of life. J Dev Physiol 1991;15:341-5.

\title{
Lowering blood homocysteine with folic acid based supplements: meta-analysis of randomised trials
}

Homocysteine Lowering Trialists' Collaboration

Participants in the collaboration are listed at the end of the paper

Correspondence to: Dr Robert Clarke,

Homocysteine Lowering Trialists' Collaboration, Clinical Trial Service Unit,

Radcliffe Infirmary, Oxford OX2 6HE robert.clarke@ctsu. ox.ac.uk

BMJ 1998;316:894-8

\begin{abstract}
Objective: To determine the size of reduction in homocysteine concentrations produced by dietary supplementation with folic acid and with vitamins B-12 or B-6.

Design: Meta-analysis of randomised controlled trials that assessed the effects of folic acid based supplements on blood homocysteine concentrations. Multivariate regression analysis was used to determine the effects on homocysteine concentrations of different doses of folic acid and of the addition of vitamin B-12 or B-6.

Subjects: Individual data on 1114 people included in 12 trials.

Findings: The proportional and absolute reductions in blood homocysteine produced by folic acid supplements were greater at higher pretreatment blood homocysteine concentrations $(\mathrm{P}<0.001)$ and at lower pretreatment blood folate concentrations $(\mathrm{P}<0.001)$. After standardisation to pretreatment blood concentrations of homocysteine of $12 \mu \mathrm{mol} / \mathrm{l}$ and of folate of $12 \mathrm{nmol} / \mathrm{l}$ (approximate average
\end{abstract}

concentrations for Western populations), dietary folic acid reduced blood homocysteine concentrations by $25 \%$ (95\% confidence interval $23 \%$ to $28 \% ; \mathrm{P}<0.001$ ), with similar effects in the range of $0.5-5 \mathrm{mg}$ folic acid daily. Vitamin B-12 (mean $0.5 \mathrm{mg}$ daily) produced an additional $7 \%$ (3\% to $10 \%$ ) reduction in blood homocysteine. Vitamin B-6 (mean $16.5 \mathrm{mg}$ daily) did not have a significant additional effect.

Conclusions: Typically in Western populations, daily supplementation with both $0.5-5 \mathrm{mg}$ folic acid and about $0.5 \mathrm{mg}$ vitamin B-12 would be expected to reduce blood homocysteine concentrations by about a quarter to a third (for example, from about $12 \mu \mathrm{mol} / \mathrm{l}$ to $8-9 \mu \mathrm{mol} / \mathrm{l})$. Large scale randomised trials of such regimens in high risk populations are now needed to determine whether lowering blood homocysteine concentrations reduces the risk of vascular disease.

\section{Introduction}

Epidemiological studies have consistently reported that patients with occlusive vascular disease have higher blood homocysteine concentrations than 
control subjects, and that these differences precede the onset of disease and are independent of other risk factors. ${ }^{1-5}$ A meta-analysis of the observational studies of blood homocysteine and vascular disease indicated that a prolonged lowering of homocysteine concentration by $1 \mu \mathrm{mol} / 1$ was associated with about a $10 \%$ reduction in risk throughout the range $10-15 \mu \mathrm{mol} / \mathrm{l} .{ }^{1}$ Blood concentrations of homocysteine are inversely related to blood concentrations of folate, vitamin B-12, and, to a lesser extent, vitamin B-6. ${ }^{6}$ Dietary supplements of these vitamins are used to reduce homocysteine concentrations in subjects with homozygous homocystinuria, who have particularly high blood concentrations of homocysteine. ${ }^{7}$ Several randomised controlled trials of the effects of folic acid based supplements on homocysteine concentrations have been conducted. Our study aimed, by a meta-analysis of data from individual participants in these trials, to determine more reliably the size of the reduction in blood homocysteine achieved with different doses of folic acid and with the addition of vitamin B-12 and vitamin B-6. This should help in the design of randomised trials of the effects of lowering homocysteine concentrations on vascular disease.

\section{Methods}

\section{Studies included}

We aimed to identify all published and unpublished randomised trials that had assessed the effects on blood homocysteine concentrations of folic acid supplements, with or without the addition of vitamins B-12 or B-6. Studies were not eligible if they did not include an untreated control group, assessed treatment after methionine loading, or treated patients for less than 3 weeks. $^{8-15}$ Eligible studies were identified by Medline searches (using search terms and widely used variants for folic acid, vitamin B-12, vitamin B-6, and homocysteine, and including the non-English language literature), scanning reference lists, and personal contact with relevant investigators. The 14 trials we identified that fulfilled the eligibility criteria $^{16-24}$ included two completed trials (involving 50 and 144 subjects; V Howard, I Brouwer, personal communications) from which data are not available for collaborative analyses until their publication. The 12 available trials included 1114 subjects. Ten of these trials had a parallel group design ${ }^{16-24}$ and two had a crossover design $^{21}$ (for which, to avoid any carryover effects, we used only data from the first period). The allocated treatment was blinded in all trials except two that had untreated controls. $^{16}{ }^{23}$

\section{Information collected}

For each subject entered in these trials, we sought details of age, sex, smoking habits, history of vascular disease or hypertension, and vitamin use before randomisation, and of their randomly allocated treatment regimen (daily dose of folic acid, vitamin B-12 or vitamin B-6, and scheduled duration) and blood concentrations of homocysteine, folate, vitamin B-12, and vitamin B-6 before treatment and at the end of the scheduled treatment period.
Table 1 Characteristics of the 12 available trials of treatment based on folic acid

\begin{tabular}{|c|c|c|c|c|c|}
\hline \multirow[b]{2}{*}{ Report } & \multirow[b]{2}{*}{$\begin{array}{l}\text { No of } \\
\text { patients }\end{array}$} & \multirow[b]{2}{*}{$\begin{array}{c}\text { Mean age } \\
\text { (years) }\end{array}$} & \multirow{2}{*}{$\begin{array}{c}\text { Treatment } \\
\text { duration } \\
\text { (weeks) }\end{array}$} & \multicolumn{2}{|c|}{ Median pretreatment concentration } \\
\hline & & & & $\begin{array}{c}\text { Homocysteine } \\
(\mu \mathrm{mol} / \mathrm{l})\end{array}$ & $\begin{array}{c}\text { Folate } \\
(\mathrm{nmol} / \mathrm{l})\end{array}$ \\
\hline Brattström $^{16}$ & 53 & 65 & 6 & 14.3 & 13.0 \\
\hline Den Heijer $I^{17}$ & 52 & 56 & 8 & 17.2 & 9.7 \\
\hline Den Heijer II ${ }^{17}$ & 178 & 53 & 8 & 11.9 & 12.7 \\
\hline Den Heijer III ${ }^{17}$ & 92 & 61 & 8 & 13.6 & 12.1 \\
\hline Ubbink I $^{18}$ & 91 & 39 & 6 & 24.9 & 4.7 \\
\hline Ubbink $\| I^{19}$ & 26 & 40 & 6 & 20.6 & 4.7 \\
\hline Naurath $^{20}$ & 285 & 75 & 3 & 12.4 & 9.7 \\
\hline$\overline{\text { Pietrzik }\left.\right|^{21}}$ & 70 & 25 & 12 & 7.4 & 23.1 \\
\hline Pietrzik $\|^{21}$ & 128 & 25 & 4 & 7.5 & 21.3 \\
\hline$\overline{\text { Woodside }^{22}}$ & 112 & 40 & 8 & 9.8 & 9.2 \\
\hline Cuskelly $^{23}$ & 17 & 23 & 12 & 5.6 & 6.4 \\
\hline Saltzman $^{24}$ & 10 & 58 & 4 & 14.4 & 19.9 \\
\hline Total & 1114 & 52 & 6 & 11.8 & 11.6 \\
\hline
\end{tabular}

\section{Statistical analysis}

The proportional reductions in blood homocysteine in the treated groups compared with the control groups were determined by extending an analysis of covariance $^{25}$ that estimated the differences in posttreatment, log transformed homocysteine values after adjustment for baseline values of homocysteine. The simple model was extended to allow the extent of this adjustment to vary between studies and to take account of factors such as folic acid dose, concomitant vitamin B-12 or vitamin B-6, age, sex, and duration of treatment. More complex models that allowed the effect of folic acid supplementation to differ in individual studies were used to investigate sources of heterogeneity.

\section{Results}

Characteristics of individual trials

Among the 1114 subjects in the trials, the mean age was 52 years (range of trial means 23 to 75 years) and the mean duration of treatment was 6 weeks (range 3 to 12 weeks) (table 1). The median pretreatment blood concentration of homocysteine was $11.8 \mu \mathrm{mol} / \mathrm{l}$ and of folate was $11.6 \mathrm{nmol} / \mathrm{l}$, but there were substantial differences between the trials. All of the trials compared folic acid alone versus control or folic acid plus vitamin B-6 or B-12, or both, versus control, although two $\operatorname{trials}^{17}$ also involved within-trial comparisons of folic acid alone versus combination therapy (table 2). A correlation coefficient of 0.87 for homocysteine in pretreatment blood samples collected from 664 of these patients on two separate occasions shows that there was relatively little variation within subjects and that the homocysteine measurements were reliable. Compliance with the study protocols was good, with blood homocysteine measurements at the end of study treatment available from $98 \%$ of those randomised.

\section{Exploration of heterogeneity between the results of different trials}

The effect of folic acid on blood homocysteine concentrations seemed to differ among the trials. This heterogeneity of the homocysteine lowering effect was not explained by differences in age, sex, or duration of treatment (although the longest duration studied was only 12 weeks). The proportional and absolute reduc- 
tions in blood homocysteine concentrations seemed, however, to be influenced by the pretreatment blood concentrations of homocysteine and folate, but not of vitamin B-12. Even after adjustment for differences in the folic acid regimen, the homocysteine lowering effect of folic acid ranged from a proportional reduction of $16 \%$ (11\% to $20 \%)$ among subjects in the bottom fifth of pretreatment blood homocysteine concentrations to a $39 \%(36 \%$ to $43 \%)$ reduction among those in the top fifth (fig 1 ; P for trend $<0.001$ ). Conversely, the blood homocysteine lowering effect of folic acid was greater at lower pretreatment blood concentrations of folate $(\mathrm{P}$ for trend $<0.001)$. These associations of the homocysteine lowering effect with pretreatment concentrations of blood homocysteine and blood folate remained significant $(\mathrm{P}<0.001)$ when both pretreatment measurements were included simultaneously in the model. The model provided no strong evidence that the variation in the homocysteine lowering effect with baseline homocysteine depended on baseline folate or vice versa. Figure 2 shows that the proportional reductions in blood homocysteine concentrations achieved by folic acid supplementation according to pretreatment blood levels of homocysteine and folate under this assumption. (Exclusion of the two trials ${ }^{18}{ }^{19}$ in subjects with very high pretreatment blood homocysteine concentrations did not materially alter these findings, and nor did inclusion of the two small completed but unpublished trials not yet formally available for these collaborative analyses: data not shown.)

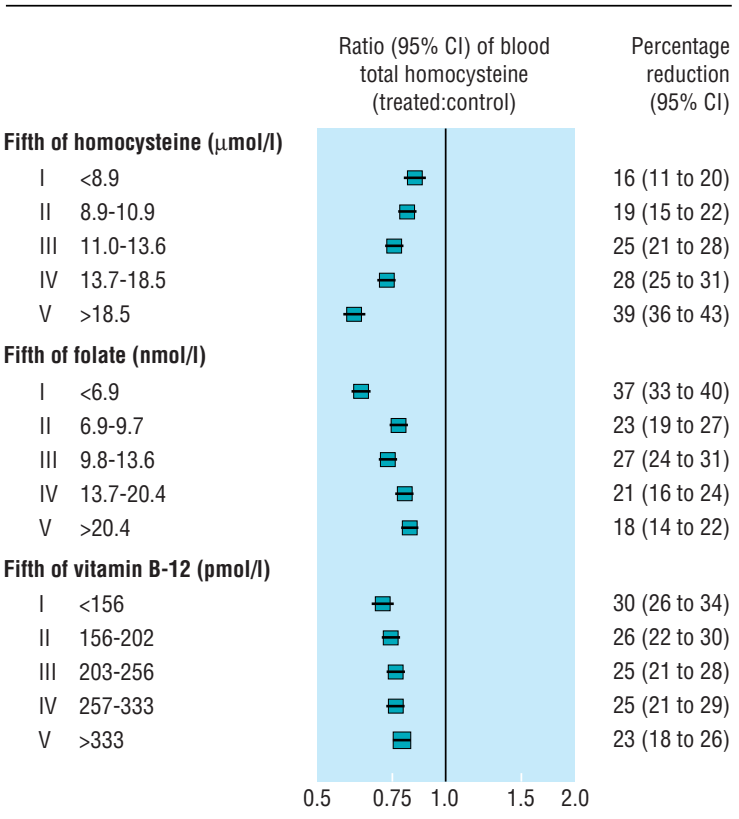

Fig 1 Reductions in blood homocysteine concentrations with folic acid supplements according to pretreatment blood concentrations of homocysteine, folate, and vitamin B-12. Squares indicate the ratios of post-treatment blood homocysteine among subjects allocated folic acid supplements to those of controls; size of square is proportional to number of subjects, and horizontal line indicates $95 \%$ confidence interval

Table 2 Blood concentrations of homocysteine in individual trials

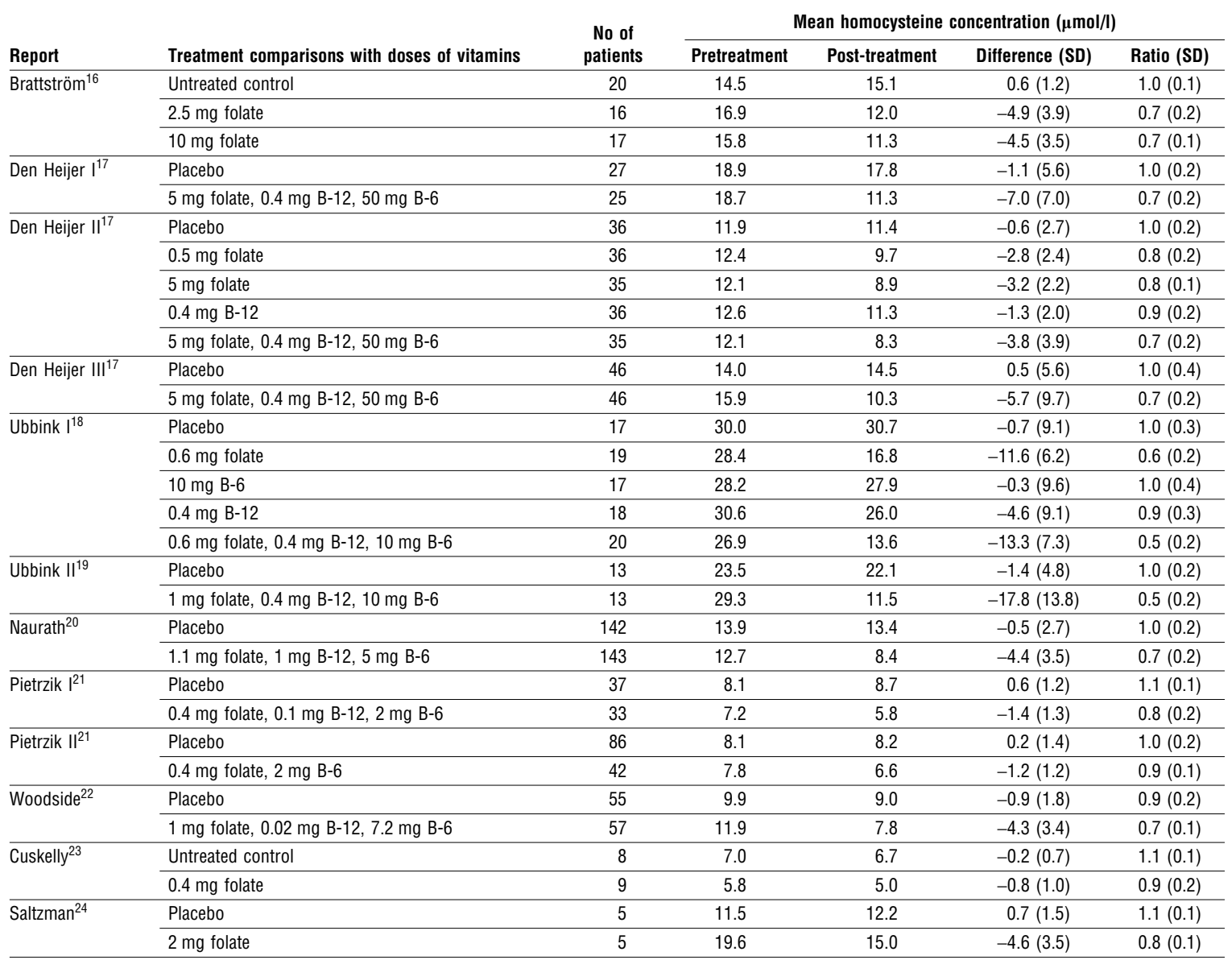




\section{Effects of different folic acid doses on blood homocysteine}

After pretreatment blood concentrations of homocysteine and folate were adjusted for, there was no longer much evidence of heterogeneity between the separate blood homocysteine lowering effects in the different trials of daily folic acid doses of $<1 \mathrm{mg}$ (mean dose $0.5 \mathrm{mg}$; $\mathrm{P}$ value for heterogeneity $=0.15)$, of $1-3 \mathrm{mg}$ (mean dose $1.2 \mathrm{mg} ; \mathrm{P}=0.05$ ), or of $>3 \mathrm{mg}$ folic acid (mean dose $5.7 \mathrm{mg} ; \mathrm{P}=0.69$ ). Nor was there any evidence of differences between the blood homocysteine lowering effects of these different folic acid doses. For individuals with pretreatment blood concentrations of homocysteine of $12 \mu \mathrm{mol} / \mathrm{l}$ and of folate of $12 \mathrm{nmol} / \mathrm{l}$ (approximate average concentrations for Western populations), folic acid doses of $<1$ $\mathrm{mg}, 1-3 \mathrm{mg}$, and $>3 \mathrm{mg}$ daily were each associated with reductions in blood homocysteine of about one quarter (fig 3).

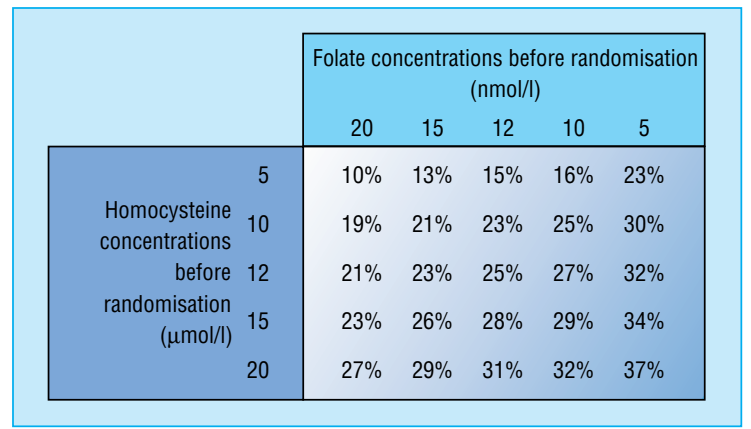

Fig 2 Predicted proportional reduction in blood homocysteine concentrations with folic acid supplementation (0.5-5 mg daily)

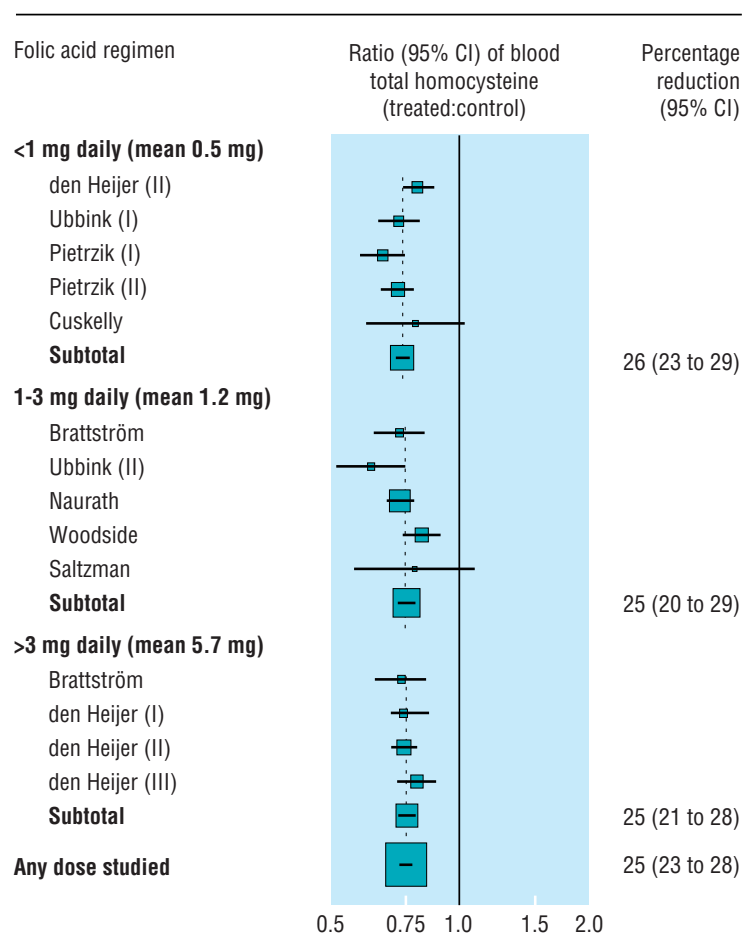

Fig 3 Reductions in blood homocysteine concentrations with varying doses of folic acid at pretreatment blood concentrations of homocysteine of $12 \mu \mathrm{mol} / \mathrm{l}$ and folate of $12 \mathrm{nmol} / \mathrm{l}$. Squares indicate the ratios of post-treatment blood homocysteine among subjects allocated folic acid supplements to those of controls; size of square is proportional to number of subjects, and horizontal line indicates $95 \%$ confidence interval

\section{Effects of adding vitamin B-12 or vitamin B-6 to folic acid}

The addition of vitamin B-12 (0.02-1 mg daily; mean $0.5 \mathrm{mg}$ ) to folic acid further reduced blood homocysteine concentrations by about $7 \%$ (3\% to $10 \%)$. Hence, among people with pretreatment blood concentrations of homocysteine of $12 \mu \mathrm{mol} / \mathrm{l}$ and of folate of $12 \mathrm{nmol} / \mathrm{l}$, adding vitamin B-12 to folic acid changed the reduction in homocysteine from 25\% (23\% to $28 \%$ ) to $31 \%(27 \%$ to $35 \%)$. Adding vitamin B-6 (2-50 mg daily; mean $16.5 \mathrm{mg}$ ) to folic acid did not lower blood homocysteine any further.

\section{Discussion}

Among the vitamins studied in these trials, folic acid had the dominant blood homocysteine lowering effect, and this effect was greater among subjects with higher blood homocysteine concentrations or lower blood folate concentrations before treatment. After standardisation for differences in pretreatment blood homocysteine and folate concentrations, the effect of folic acid was similar for daily doses ranging from 0.5 to $5 \mathrm{mg}$ daily, and vitamin B-12 produced a small additional effect. Supplementation with vitamin B-6 did not seem to have any material effect on blood homocysteine concentrations, but these trials did not assess effects on blood homocysteine after methionine loading, which may be determined to a greater extent by the transulphuration pathway in which vitamin B-6 is a cofactor.

Our results suggest that a daily dose of at least $0.5 \mathrm{mg}$ of folic acid, along with a similar amount of vitamin B-12, would produce a proportional reduction in blood homocysteine of about a quarter to a third. The addition of about $1 \mathrm{mg}$ daily of oral vitamin B-12 to folic acid would also be expected to avoid the theoretical risk of neuropathy due to unopposed folic acid therapy in patients deficient in vitamin B-12, even those with intrinsic factor deficiency or malabsorption states. ${ }^{26-28}$ Studies in the United States and Britain indicate that the average concentration of blood homocysteine in a typical Western population is about $12 \mu \mathrm{mol} / \mathrm{l},{ }^{4}{ }^{6}$ and so a reduction of about a quarter to a third would correspond to an absolute reduction of about $3-4 \mu \mathrm{mol} / \mathrm{l}$. A previous meta-analysis of the observational studies suggests that a prolonged lower blood homocysteine concentration of $3-4 \mu \mathrm{mol} / 1$ would correspond to $30-40 \%$ less vascular disease. ${ }^{1}$ Consequently, even if as much as half of the epidemiologically predicted benefit is achieved within a few years of lowering blood homocysteine (as seems to be the case with cholesterol lowering ${ }^{29-31}$ ), trials of folic acid supplements may well need to be large, and to include people at high risk, to be able to detect the sort of reductions- $15 \%$ to $20 \%$-in cardiovascular risk that might realistically be anticipated.

Supplementation with folic acid is a cheap and effective method of lowering blood homocysteine concentrations. If large scale trials in high risk populations do show reliably that blood homocysteine reductions with such supplements can be sustained over time and that this strategy reduces the risk of vascular events (and is safe), this could have important public health implications. Higher dose supplements could be used in people at high risk, and population mean 
4 Perry I, Refsum H, Morris RW, Ebrahim S, Ueland PM, Shaper AG. A prospective study of serum homocysteine concentration and risk of

stroke in middle-aged men. Lancet 1995;346:1395-8.

- Higher blood homocysteine concentrations seem to be associated with higher risks of occlusive vascular disease and with lower blood concentrations of folate and vitamins B-12 and B-6

- Proportional and absolute reductions in blood homocysteine concentrations with folic acid supplements are greater at higher pretreatment blood homocysteine concentrations and at lower pretreatment blood folate concentrations

- In typical Western populations, supplementation with both $0.5-5 \mathrm{mg}$ daily folic acid and about $0.5 \mathrm{mg}$ daily vitamin B-12 should reduce blood homocysteine concentrations by about a quarter to a third

- Large scale randomised trials of such regimens in people at high risk are now needed to determine whether lowering blood homocysteine concentrations reduces the risk of vascular disease

concentrations of blood homocysteine could be reduced by fortifying flour with folic acid. ${ }^{132}$ Introducing fortified flour for the prevention of neural tube defects before trials of folic acid on vascular disease are conducted could, however, complicate the overall assessment of any benefits-or risks-of lowering homocysteine concentrations in this way.

The following investigators were members of the Homocysteine Lowering Trialists' Collaboration. Abbreviated trial names are listed alphabetically, along with the institutions and names of the principal investigators. Brattström (University of Lund: L Brattström, F Landgren, B Israelsson, A Lindgren, B Hultberg, A Andersson); Cuskelly (University of Ulster: G Cuskelly, H McNulty, SS Strain; Trinity College, Dublin: J McPartlin, DG Weir, JM Scott); den Heijer (Leyenburg Hospital, the Hague, and University of Nijmegen: $\mathrm{M}$ den Heijer, IA Brouwer, HJ Blom, GMJ Bos, A Spaans, FR Rosendaal, CMG Thomas, HL Haak, PW Wijermans, WBJ Gerrits); Naurath (University of Leuven and Witten-Herdecke: HJ Naurath, E Joosten, R Riezler, SP Stabler, RH Allen, J Lindenbaum); Pietrzik (University of Bonn: K Pietrzik, R Prinz-Langenohl, J Dierkes); Saltzman (USDA-HNRC at Tufts University: E Saltzman, JB Mason, P Jacques, J Selhub, D Salem, E Schaefer, IH Rosenberg); Ubbink (University of Pretoria: J Ubbink, A van der Mere, WJH Vermack, R Delport, PJ Becker, HC Potgieter); Woodside (Queen's University of Belfast: JV Woodside, JWG Yarnell, D McMaster, IS Young, EE McCrum, SS Patterson, KF Gey, AE Evans).

Secretariat: Clinical Trial Service Unit, University of Oxford (R Clarke, P Appleby, P Harding, P Sherliker, R Collins) and Medical Statistics Unit, London School of Hygiene and Tropical Medicine (C Frost, V Leroy).

Writing committee and guarantors: R Clarke, C Frost, V Leroy, R Collins.

This paper is dedicated to the late Dr John Lindenbaum. Funding: British Heart Foundation and Medical Research Council.

$$
\text { Conflict of interest: None. }
$$

1 Boushey CJ, Beresford SA, Omen GS, Motulsky AG. A quantitative assessment of plasma homocysteine as a risk factor for vascular disease. Probable benefits of increasing folic acid intakes. JAMA 1995;274:104957.

2 Clarke R, Daly L, Robinson K, Naughten E, Cahalane S, Fowler B, et al. Hyperhomocysteinemia: an independent risk factor for vascular disease. NEngl J Med 1991;324:1149-55.

3 Arnesen E, Refsum H, Bonaa KH, Ueland PM, Forde OH, Nordrehaug $\mathrm{JE}$, et al. Serum total homocysteine and coronary heart disease. Int J Epidemiol 1995;24:704-9.
5 Graham IM, Daly LE, Refsum H, Robinson K, Brattström LE, Ueland PM, et al. Plasma homocysteine as a risk factor for vascular disease. JAMA 1997;277:1775-81.

6 Selhub J, Jacques PF, Wilson PW, Rush D, Rosenberg IH. Vitamin status and intake as primary determinants of homocysteinemia in an elderly population. JAMA 1993;270:2693-8.

7 Mudd SH, Skovby F, Levy HL, Pettigrew KD, Wilcken B, Pyeritz RE, et al. The natural history of homocystinuria due to cystathionine beta-synthase deficiency. Am J Hum Genet 1985;37:1-31.

8 van der Berg M, Franken DG, Boers GHJ, Blom HJ, Jakobs C, Stehouwer CDA, et al. Combined vitamin $B_{6}$ and folic acid therapy in young patients with arteriosclerosis and hyperhomocysteinemia. J Vasc Surg 1994;20:933-40.

9 Franken DG, Boers GHJ, Blom HJ, Trijbels FJM Kloppenberg PW. Treatment of mild hyperhomocysteinemia in vascular disease patients. Arteriosclerosis Thromb 1994;14:465-70.

10 Wilcken DEL, Dudman NPB, Tyrell PA, Robertson MR. Folic acid lowers plasma homocysteine in chronic renal insufficiency: possible implications for the prevention of vascular disease. Metabolism 1988;37:697-701.

11 Brattström L, Israelsson B, Jeppson JU, Hultberg BL. Folic acid-an innocuous means of reducing plasma homocysteine. Scand J Clin Lab Invest 1988;48:215-21.

12 Arnadottir M, Brattström L, Simonsen O, Thysell H, Hultberg B, Andersson A, et al. The effect of high-dose pyridoxine and folic acid supplementation on serum lipids and plasma homocysteine. Clin Nephrol 1993;40:236-40.

13 Bostom AG, Shemin D, Lapane KL, Hume AL, Yoburn D, Nadeau MR, et al. High dose B-vitamin treatment of hyperhomocysteinemia in dialysis patients. Kidney Int 1996;49:147-52.

14 Chaveau P, Chadefoux-Vekemans B, Coude M, Aupetit J, Kamoun P, Jungers P. Hyperhomocysteinemia in chronic renal failure patients. Reduction of vascular risk factors by folate supplementation. Ir J Med Sci 1995; $164: 25$.

15 Ryan M, Robinson K, Clarke R, Refsum H, Ueland P, Graham I. Vitamin $\mathrm{B}_{6}$ and folate reduce homocysteine concentrations in coronary artery disease. Ir J Med Sci 1993;162:197.

16 Landgren F, Israelsson B, Lindgren A, Hultberg B, Andersson A, Brattström L. Plasma homocysteine in acute myocardial infarction: homocysteine-lowering effect of folic acid.J Intern Med 1995;237:381-8.

17 Den Heijer M, Brouwer IA, Bos GMJ, Blom HJ, Spaans AP, Rosendaal FR, et al. Vitamin supplementation reduces blood homocysteine levels: a controlled trial in patients with venous thrombosis and healthy volunteers. Arteriosclerosis Thromb Vascular Biol (in press).

18 Ubbink JB, Vermaak WJH, van der Merwe A, Becker PJ, Delport R, Potgieter HC. Vitamin requirements for the treatment of hyperhomocysteinemia in humans. J Nutr 1994,124:1927-33.

19 Ubbink JB, van der Merwe A, Vermaak WJH, Delport R. Hyperhomocysteinemia and the response to vitamin supplementation. Clin Invest 1993;71:993-8

20 Naurath HJ, Joosten E, Riezler R, Stabler SP, Allen RH, Lindenbaum J Effects of vitamin $B_{12}$, folate, and vitamin $B_{6}$ supplements in elderly people with normal serum vitamin concentrations. Lancet 1995;346:85-9.

21 Dierkes J. Vitamin requirements for the reduction of homocysteine blood levels in healthy young women [dissertation]. Bonn: University of Bonn, 1995.

22 Woodside JV, Yarnell JWG, Young IS, McCrum EE, Patterson CC, Gey F, et al. The effects of oral vitamin supplementation on cardiovascular risk factors. Proc Nutr Soc 1997;56:149A.

23 Cuskelly G, McNulty W, McPartlin J, Strain JJ, Scott JM. Plasma homocysteine response to folate intervention in young women. Ir J Med Sci 1995; $164: 3$.

24 Saltzman E, Mason JB, Jacques PF, Selhub J, Salem D, Schaefer EJ, et al. $\mathrm{B}$ vitamin supplementation lowers homocysteine levels in heart disease. Clin Res 1994;42:172A.

25 Frison L, Pocock SJ. Repeated measures in clinical trials: analysis using mean summary statistics and its implications for design. Statistics in Medicine 1992;11:1685-704

26 Lindenbaum J, Healton EB, Savage DG, Brust JCM, Garrett TJ, Podell ER, et al. Neuropsychiatric disorders caused by cobalamin deficiency in the absence of anemia or macrocytosis. N Engl J Med 1988:318:1720-8.

27 Savage DG, Lindenbaum J. Folate-cobalamin interactions: In: Bailey LB, ed. Folate in health and disease. New York: Marcel Dekker, 1995:237-85.

28 Cambell NRC. How safe are folic acid supplements? Arch Intern Med 1996;156:1638-44.

29 Scandinavian Simvastatin Survival Study Group. Randomised trial of cholesterol lowering in 4444 patients with coronary heart disease: the Scandinavian simvastatin survival study (4S). Lancet 1994;344:1383-9.

30 Sacks FM, Pfeffer MA, Moye LA, Rouleau JL, Rutherford JD, Cole TG, et al. The effects of pravastatin on coronary events after myocardial infarction in patients with average cholesterol levels. $N$ Engl J Med 1996;335:1001-9.

31 Shepherd J, Cobbe SM, Ford I, Isles CG, Lorimer AR, Macfarlane PW, et al for the West of Scotland Coronary Prevention Study Group. Prevention of coronary heart disease with pravastatin in men with hypercholesterolemia. N Engl J Med 1995;333:1301-7.

32 Tucker KL, Mahnken B, Wilson PWF, Jacques P, Selhub J. Folic acid fortification of the food supply: potential benefits and risks for the elderly

(Accepted 27 November 1997) population. JAMA 1996;276:1879-85. 